Polymer Journal, Vol. 23, No. 11, pp 1383-1386 (1991)

\title{
NOTES
}

\section{Ring-Opening Copolymerization of Anhydroribose Derivatives}

\author{
Kenichi Hatanaka and Toshiyuki Uryu* \\ Department of Biomolecular Engineering, Tokyo Institute of Technology, \\ Nagatsuta, Midori-ku, Yokohama 227, Japan \\ * Institute of Industrial Science, University of Tokyo, \\ Roppongi, Minato-ku, Tokyo 106, Japan
}

(Received May 9, 1991)

\begin{abstract}
KEY WORDS Anhydrosugar / Ring-Opening Polymerization / Copolymerization / Ribose / Cellulose / Polysaccharide /
\end{abstract}

Ring-opening polymerization of 1,4-anhydrosugar derivative, which is equally regarded as a 1,5-anhydrosugar derivative, has been carried out to afford a polysaccharide. There are four possible monomeric units in the polymer, i.e., 1,5- $\alpha$ - and 1,5- $\beta$-furanosidic and $1,4-\alpha$ - and 1,4- $\beta$-pyranosidic units, as described previously. ${ }^{1}$ The structure of the polymer was attributed to the kind of sugar, protective group, and polymerization conditions, which were catalyst, temperature, and time. Usually, a thermodynamically stable furanan-type polymer is preferencially formed. ${ }^{2-7}$ Among several investigations of the polymerization of 1,4-anhydrosugar derivatives, only two kinds of sugars, i.e., ribose ${ }^{7,8}$ and 6-deoxytalose, ${ }^{1}$ were able to be polymerized to give cellulosetype polymers.

Ring-opening polymerization of 1,4-anhydro-2,3- $O$-benzylidene- $\alpha$-D-ribopyranose (ABRP) with antimony pentachloride as catalyst gave the first artificial cellulose-type polysaccharide. ${ }^{8}$ Selective $\beta$-1,4-scission was caused by two factors: (1) selective coordination of $\mathrm{SbCl}_{5}$ among three oxygens, which are 1,4-linked oxygen, $\mathrm{O}-2$, and $\mathrm{O}-3$ in an initiation step and (2) formation of an oxonium ion at the $\mathrm{O}-4$ oxygen at the growing chain end.

On the other hand, the polymerization of 1,4-anhydro-2,3-di- $O$-benzyl- $\alpha$-D-ribopyranose
(ADBR) gave $(1 \rightarrow 5)-\alpha$-D-ribofuranan with any catalyst at low temperatures. ${ }^{6}$ 1,4-Anhydro2,3-di- $O$ - $t$-butyldimethylsilyl- $\alpha$-D-ribopyranose (ADSR) was polymerized with appropriate catalysts to give both stereoregular $(1 \rightarrow 4)-\beta$-D-ribopyranan and $(1 \rightarrow 5)-\alpha$-D-ribofuranan derivatives. ${ }^{7}$

Recently, we reported that the selective ring-opening copolymerization of $\mathrm{ABRP}$ and ADSR with $\mathrm{SbCl}_{5}$ as catalyst at $0^{\circ} \mathrm{C}$ has given stereoregular copolymers with 1,4- $\beta$-pyranosidic structure (cellulose-type). ${ }^{9}$

In this study, we report that the copolymerization of ABRP and ADBR with $\mathrm{SbCl}_{5}$ as catalyst at several temperatures to give a copoly(ABRP-ADBR). Structure analysis of the copolymer is performed by ${ }^{13} \mathrm{C}$ NMR spectroscopy and optical rotation.

\section{EXPERIMENTAL}

1,4-Anhydro- $\alpha$-D-ribopyranose (ribosan) was prepared by the pyrolysis of D-ribose under reduced pressure. Benzylidination of ribosan was carried out with $\alpha, \alpha$-dimethoxytoluene and $p$-toluenesulfonic acid in DMF to give ABRP monomer. ADBR monomer was synthesized by benzylation of ribosan with benzyl bromide and sodium hydride in DMF.

Copolymerization was carried out under 
Table I. Copolymerization of 1,4-anhydro-2,3-O-benzylidene- $\alpha$-D-ribopyranose (ABRP) with 1,4-anhydro-2,3-di- $O$-benzyl- $\alpha$-D-ribopyranose (ADBR) ${ }^{\mathbf{a}}$

\begin{tabular}{|c|c|c|c|c|c|c|c|c|c|c|}
\hline \multirow{3}{*}{ No. } & \multirow{3}{*}{$\begin{array}{l}\begin{array}{c}\text { ABRP in } \\
\text { monomer } \\
\text { feed }\end{array} \\
\text { mol } \%\end{array}$} & \multirow{3}{*}{$\frac{\text { Temp }}{{ }^{\circ} \mathrm{C}}$} & \multirow{3}{*}{$\frac{\text { Yield }}{\%}$} & \multirow{3}{*}{$\frac{[\alpha]_{\mathrm{D}}^{25}}{\operatorname{deg}}$} & \multirow{3}{*}{$\begin{array}{c}\bar{M}_{n}^{\mathrm{b}} \\
\left(\times 10^{3}\right)\end{array}$} & \multirow{3}{*}{$\begin{array}{l}\text { ABRP unit } \\
\text { in copolymer } \\
\text { mol } \%\end{array}$} & \multicolumn{4}{|c|}{ Stereoregularity $/ \%$} \\
\hline & & & & & & & \multicolumn{2}{|c|}{ ABRP } & \multicolumn{2}{|c|}{ ADBR } \\
\hline & & & & & & & $1,4-\beta$ & $1,5-\alpha$ & $1,4-\beta$ & $1,5-\alpha$ \\
\hline 1 & 33 & 0 & 19.1 & -11.2 & & 67 & 100 & 0 & 100 & 0 \\
\hline 2 & 50 & 0 & 28.7 & -28.0 & 6.4 & 82 & 100 & 0 & 100 & 0 \\
\hline 3 & 67 & 0 & 42.5 & -39.2 & 6.9 & 90 & 100 & 0 & 100 & 0 \\
\hline 4 & 50 & -20 & 38.9 & -3.1 & 7.7 & 64 & 100 & 0 & 82 & 18 \\
\hline 5 & 50 & -40 & 54.0 & -10.1 & 11.8 & 45 & 97 & 3 & 29 & 71 \\
\hline 6 & 50 & -60 & 78.4 & +66.5 & & 39 & 89 & 11 & 19 & 81 \\
\hline 7 & 67 & -60 & 67.3 & +28.3 & 4.3 & 64 & 95 & 5 & 29 & 71 \\
\hline
\end{tabular}

${ }^{\text {a }}$ Monomer $(0.5 \mathrm{~g})$ concentration, $50 \mathrm{w} / \mathrm{v} \%$; solvent, methylene chloride; catalyst, antimony pentachloride; time, $3 \mathrm{~h}$.

b Determined by GPC.

high vaccum at low temperature in anhydrous methylene chloride with antimony pentachloride as described previously. ${ }^{1-8}$ The copolymerization was terminated by the addition of methanol. The polymer solution in chloroform was neutralized with aqueous sodium hydrogen carbonate solution and washed with water. The polymer was purified by reprecipitation using chloroform-methanol system, and then it was finally freeze dried from benzene.

$67.5 \mathrm{MHz}{ }^{13} \mathrm{C}$ NMR spectra were recorded on a JEOL GX-270 spectrometer in chloroform- $d$ using tetramethylsilane as the internal standard. Optical rotations were measured in chloroform at $25^{\circ} \mathrm{C}$ with Perkin-Elmer Model 241 polarimeter using 1-dm cell.

\section{RESULTS AND DISCUSSION}

Copolymerization of ABRP and ADBR was carried out with antimony pentachloride as catalyst in methylene chloride at low temperatures under high vacuum. The results are summarized in Table I. Copolymer composition, i.e., mole fraction of ABRP unit in the copolymer, and stereoregularity of each monomeric unit were determined by ${ }^{13} \mathrm{C} N \mathrm{NMR}$ spectroscopy.
When mole fraction of ABRP in feed was 0.50 , increasing polymerization temperature tended to increase mole fraction of ABRP in copolymer and to decrease the polymer yield, indicating that the ring-opening polymerizability of ADBR monomer relatively low at higher temperatures. It can be accounted for by degradation of the polymer, in the same way as the case of homopolymerization of ADBR with $\mathrm{SbCl}_{5}$ around $0^{\circ} \mathrm{C} .{ }^{6}$

${ }^{13} \mathrm{C}$ NMR spectra (acetal carbon region) of copoly(ABRP-ADBR) prepared at several temperatures are shown in Figure 1. In the spectra of the copolymers prepared at relatively lower temperatures, the C-1 absorption due to 1,5- $\alpha$-furanosidic structure of ADBR unit was observed at $101.7 \mathrm{ppm}$. On the other hand, in the spectrum of the copolymer obtained at $0^{\circ} \mathrm{C}$, there were no $1,5-\alpha$ peaks at $101.7 \mathrm{ppm}$, indicating that ADBR unit at the growing chain end caused $\beta-1,4$-scission at $0^{\circ} \mathrm{C}$, giving a polymer with regular structure. The absorption of methine carbon of benzylidene group in 1,5- $\alpha$-furanosidic unit of ABRP was not observed in the spectrum of the copolymer except the copolymer synthesized at lower temperatures, indicating that ABRP unit made $\beta$-1,4-scission at higher temperature. There- 

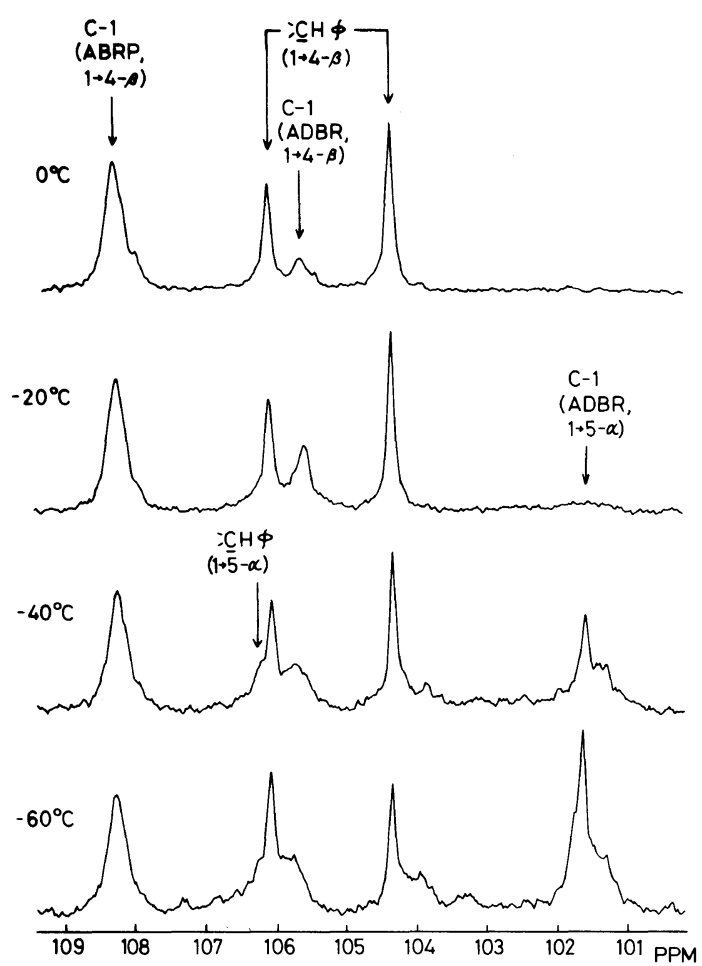

Figure 1. ${ }^{13} \mathrm{C}$ NMR spectra (acetal carbon region) of copoly(ABRP-ADBR) prepared at various temperatures.

fore, the copolymerization of ABRP and ADBR (1:1 in monomer feed) with $\mathrm{SbCl}_{5}$ at $0^{\circ} \mathrm{C}$ was found to give a stereoregular $(1 \rightarrow 4)$ - $\beta$-D-ribofuranan derivative.

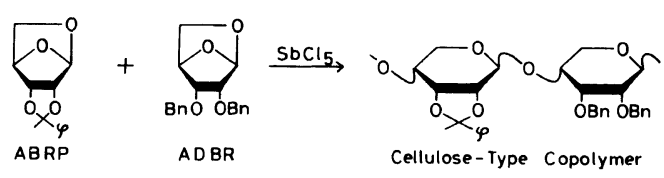

As shown in Table I and Figure 2, in the copolymerization of $\mathrm{ABRP}$ and $\mathrm{ADBR}$ at $0^{\circ} \mathrm{C}$, both ABRP and ADBR gave 1,4- $\beta$-pyranosidic units in every monomer fraction in feed. At $0^{\circ} \mathrm{C}$ ABRP monomer seemed to be more reactive than ADBR monomer. The monomer reactivity ratios of $A B R P\left(M_{1}\right)$ and $A D B R$ $\left(\mathrm{M}_{2}\right)$ at $0^{\circ} \mathrm{C}$ were evaluated by the KelenTüdös method, ${ }^{10}$ which is applicable to that data in relatively high conversions. The monomer reactivity ratios were $r_{1}=4.9 \pm 0.5$
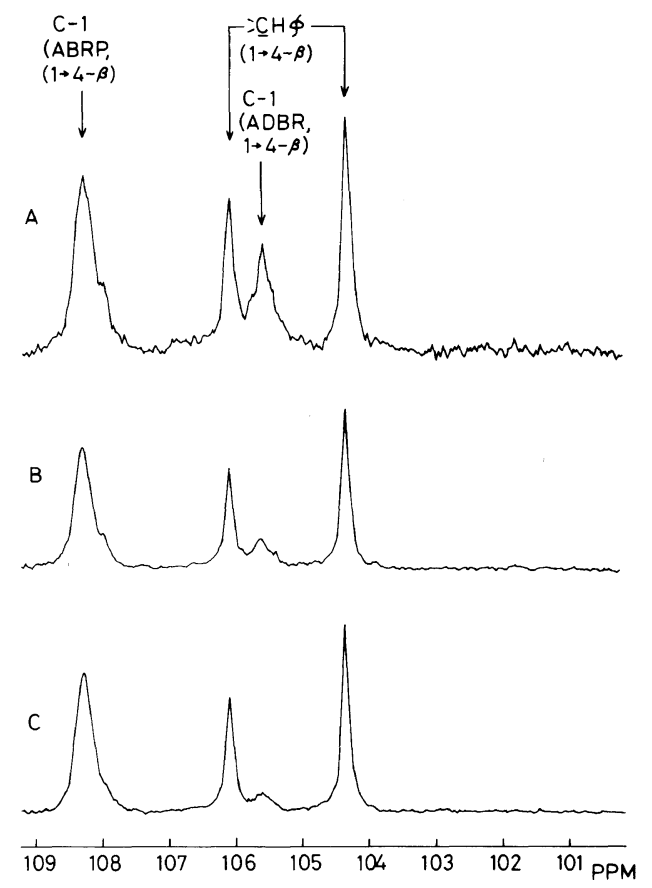

Figure 2. ${ }^{13} \mathrm{C}$ NMR spectra (acetal carbon region) of stereoregular copoly(ABRP-ADBR) with various composition prepared at $0^{\circ} \mathrm{C}$. (A, no. 1 ; B, no. 2 ; C, no. 3 in Table I.)

and $r_{2}=0.3 \pm 0.1$. The $r_{2}$ value indicates that the ADBR monomer hardly attaches to the growing chain end consisting of the ADBR unit to open the 1,4-anhydro ring, i.e., ADBR monomer has low homopolymerizability at this condition $\left(\mathrm{SbCl}_{5}\right.$ catalyst, $\left.0^{\circ} \mathrm{C}\right)$. And it also manifests that most ADBR units are distributed as single units through the main chain of the copolymer. Dependence of the monomer fraction in feed on the number-average sequence length of each component, which was calculated using the monomer reactivity ratios, is shown in Table II. It reveals that the number-average sequence length of ADBR unit was less than 2 over a wide range of monomer fraction in feed.

In conclusion, it was found that ring-opening copolymerization of 1,4-anhydroribose derivatives with $\mathrm{SbCl}_{5}$ as catalyst at $0^{\circ} \mathrm{C}$ gave a stereoregular $(1 \rightarrow 4)-\beta$-linked (cellulose type) 
Table II. Number average sequence length in copoly(ABRP-ADBR) $\left(r_{\mathrm{ABRP}}=4.9, r_{\mathrm{ADBR}}=0.3\right)^{\mathrm{a}}$

\begin{tabular}{|c|c|c|c|c|c|}
\hline \multicolumn{2}{|c|}{$\begin{array}{l}\text { Mole fraction } \\
\text { in monomer feed }\end{array}$} & \multicolumn{2}{|c|}{$\begin{array}{l}\text { Mole fraction } \\
\text { in copolymer }\end{array}$} & \multicolumn{2}{|c|}{$\begin{array}{l}\text { Number average } \\
\text { sequence length }\end{array}$} \\
\hline ABRP & ADBR & ABRP & ADBR & ABRP & ADBR \\
\hline 0.33 & 0.67 & 0.67 & 0.33 & $3.5 \pm 0.3$ & $1.6 \pm 0.2$ \\
\hline 0.50 & 0.50 & 0.82 & 0.18 & $5.9 \pm 0.5$ & $1.3 \pm 0.1$ \\
\hline 0.67 & 0.33 & 0.90 & 0.10 & $10.8 \pm 1.0$ & $1.2 \pm 0.1$ \\
\hline
\end{tabular}

${ }^{a}$ Catalyst, $\mathrm{SbCl}_{5}$; temperature, $0^{\circ} \mathrm{C}$.

copolymer, which can be used as a starting material of chemical synthesis of branched cellulose-type polysaccharide. ADBR monomer showed lower reactivity than ABRP monomer at $0^{\circ} \mathrm{C}$, while ADSR had the similar reactivity to $A B R P$ in the copolymerization of $0^{\circ} \mathrm{C}^{9}$

\section{REFERENCES}

1. M. Ogawa, K. Hatanaka, and T. Uryu, Macromolecules, 24, 987 (1991).

2. T. Uryu, J. Yamanouchi, S. Hayashi, H. Tamaki, and K. Matsuzaki, Macromolecules, 16, 320 (1983).

3. Y. Koyama, K. Harima, K. Matsuzaki, and T. Uryu, J. Polym. Sci., Polym. Chem. Ed., 23, 2989 (1985).

4. A. Hagino, S. Yoshida, T. Shinpuku, K. Matsuzaki, and T. Uryu, Macromolecules, 19, 1 (1986).

5. T. Uryu, C. Yamaguchi, K. Morikawa, K. Terui, T. Kanai, K. Matsuzaki, Macromolecules, 18, 599 (1985).

6. T. Uryu, J. Yamanouchi, T. Kato, S. Higuchi, and K. Matsuzaki, J. Am. Chem. Soc., 105, 6865 (1983).

7. T. Uryu, M. Yamanaka, M. Date, M. Ogawa, and K. Hatanaka, Macromolecules, 21, 1916 (1988).

8. T. Uryu, K. Kitano, K. Ito, J. Yamanouchi, and K. Matsuzaki, Macromolecules, 14, 1 (1981).

9. T. Yoshida, L. Song, C. P. Wu, K. Hatanaka, and T. Uryu, Chem. Lett., 477 (1991).

10. T. Kelen and F. Tüdös, J. Macromol. Sci. Chem., A9, 1 (1975). 